\title{
Regional-scale weather patterns and wildland fires in central Portugal
}

\author{
Klaus P. Hoinka ${ }^{\mathrm{A}} \mathrm{C}$, Anabela Carvalho ${ }^{\mathrm{B}}$ and Ana Isabel Miranda ${ }^{\mathrm{B}}$ \\ A Institut für Physik der Atmosphäre, Deutsches Zentrum für Luft- und Raumfahrt (DLR), \\ Postfach 1116, D-82230 Wessling, Oberpfaffenhofen, Germany. \\ ${ }^{B}$ Centro de Estudos do Ambiente e do Mar (CESAM) and Department of Environment \\ and Planning, University of Aveiro, PT-3810-193 Aveiro, Portugal. \\ ${ }^{\mathrm{C} C o r r e s p o n d i n g ~ a u t h o r . ~ E m a i l: ~ k l a u s . h o i n k a @ d l r . d e ~}$
}

\begin{abstract}
The characteristic evolution of the synoptic- and meso-scale wind, temperature and humidity pattern during wildland fire events in Portugal was determined by lagged covariances for the period 1980 to 2001. The daily burnt area was chosen as the parameter to be correlated with atmospheric fields provided by the European Centre for Medium-Range Weather Forecasts Reanalysis (ERA40) data. The related time series consisted of wildland fires with a daily burnt area of more than 500 ha in central Portugal. Five days in advance of a fire event, a strong positive anomaly existed in the surface pressure and in the 500-hPa geopotential field, both appearing to the west of the Iberian Peninsula and moving towards Brittany until lag zero. In advance of the fire event, the flow above Portugal came from the north, turning to easterlies at lag time zero and finally coming from the south-east during the post-event phase. Surface wind statistics taken at Castelo Branco supported these results. Smoke plumes from wildland fires detected by satellites indicated a similar flow structure, which was quite different to the averaged summertime flow above Portugal. Cross-covariance regression between the Iberian thermal low and burnt area showed that the peak amount of burnt area occurred up to 3 days after the appearance of a thermal low. This suggested that in the pre-phase of a wildland fire, heated air is transported from the peninsula's centre towards Portugal.
\end{abstract}

\section{Introduction}

A major environmental concern in the Mediterranean is the occurrence of devastating summertime wildland fires. Spain and Portugal register $\sim 50 \%$ of the largest number of fires in the European region (EC 1998). During the period 1980-2000, the mean area burnt by wildland fires in Portugal was higher than 90000 ha per year (Pereira et al. 2005). Forest land in Portugal occupies $\sim 5.4 \times 10^{6}$ ha, which represents two-thirds of continental Portugal's surface. In central Portugal, $\sim 25 \%$ of its surface is covered by pine trees (Pinus pinaster) and eucalyptus (Eucalyptus globulus) (Carvalho et al. 2008). The outbreak of a fire depends on the fuel loading of a region and on local temperature and humidity conditions.

Diverse scales of motion influence a wildland fire's behavior, from the large-scale weather pattern $(\sim 1000 \mathrm{~km})$ down to the local fire-generated flow of a few tens of metres. Therefore, several studies have addressed correlations between synoptic-, meso-, and local-scale weather and wildland fire. Brotak and Reifsnyder (1977) showed that $80 \%$ of the major fires in the eastern United States occurred related to frontal passages that were associated with a trough at the $500-\mathrm{hPa}$ surface. For Canada, statistically significant positive correlations were established between burnt area and the 500-hPa anomaly series (Skinner et al. 1999). In a further study, Skinner et al. (2002) analysed monthly mean burned areas in conjunction with zonal indices. Pereira et al. (2005) discussed synoptic conditions associated with Portugal's wildland fires and investigated the link between winter and spring precipitation intensity and the wildland fire occurrence during the following summer. Flannigan and Wotton (2001) investigated the connection between climate-weather and the area burnt by forest fires. Small-scale atmosphere-fire interactions and feedbacks are studied in Jenkins et al. (2001). Trigo et al. (2006) pointed out that during the devastating 2003 fire season in Portugal, the days with highest amounts of area burned were characterized by large anomalies in the surface maximum and minimum temperature, relative humidity, and wind speed and direction.

It is a standard method in meteorology to calculate lagged covariances and correlations of meteorological fields with parameters or with single station time series (von Storch and Zwiers 1999). In the present study atmospheric parameter fields, such as temperature, humidity and wind are correlated with time series of wildland fire data in Portugal. The calculations describe the statistically relevant evolution of atmospheric fields associated with wildland fires. This allows the determination of the pre-event situation as well as development after the fire's outbreak. In particular, the results of this method will explain flow features above Portugal as derived from smoke plumes of forest fires, detected by recently available satellites. It is shown also that the fire-related statistical flow is quite different to that characteristic for the summertime.

Because the Iberian thermal low is the dominating regionalscale summertime feature (Hoinka and Castro 2003), it is worthwhile to investigate if there is a link between the heat 


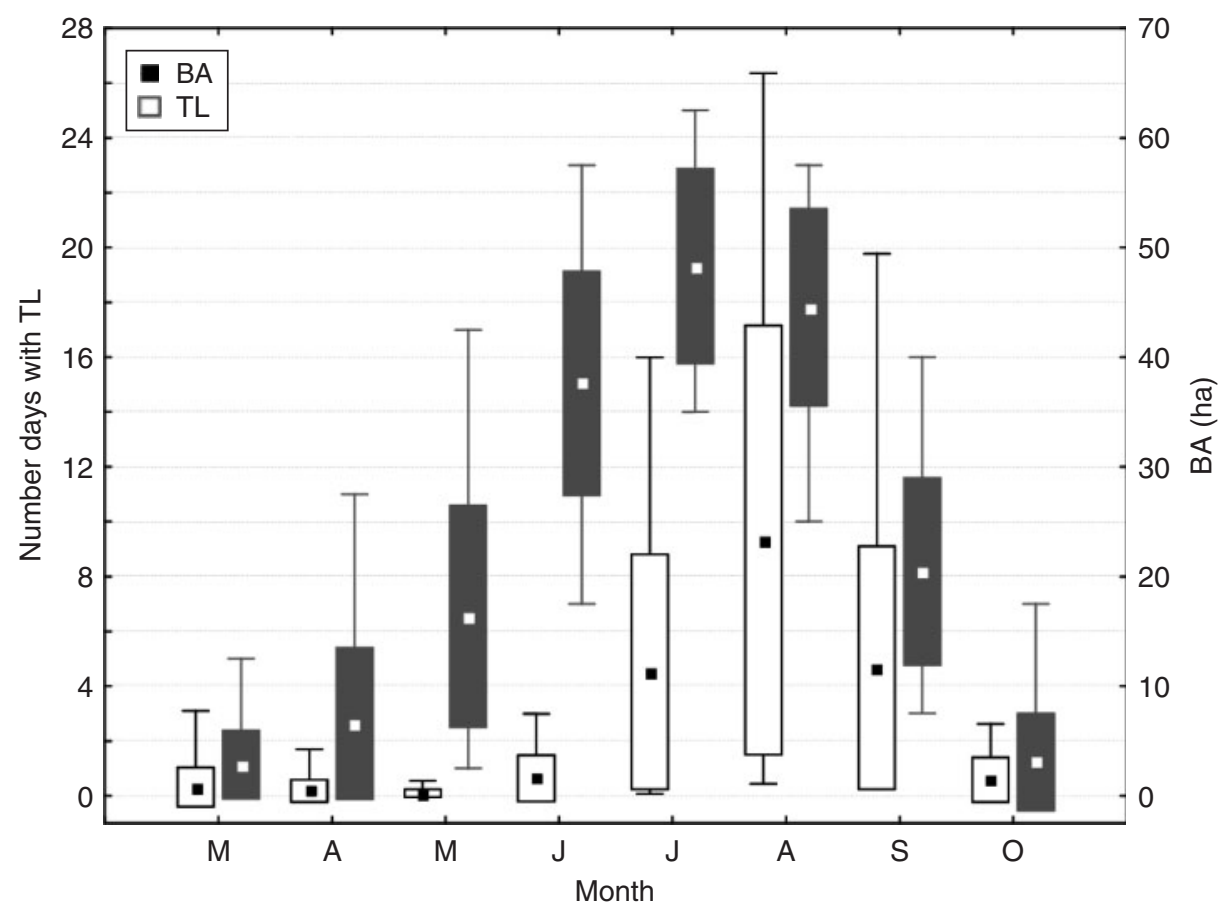

Fig. 1. Mean monthly burnt area (BA) in five districts of central Portugal and mean monthly number of days with thermal lows (TL) derived from ERA40 data (see text) between 1980 and 2001: mean value; standard deviation (elongated box); and minima and maxima.

depression and the occurrence of wildfires in Portugal. This is particularly meaningful, because the surface conditions of the heat low are characterized by dry and hot weather that is favorable for wildland fire outbreak. However, the circulation associated with thermal lows forces (above Portugal) a weak surface flow towards the centre of the Iberian Pensinsula (IP). This flow is in contrast to that observed during wildland fires by Portuguese firemen and to data provided by satellites. These observations show a significant surface flow from the east entering Portugal. Thus, a second aim is to study the impact of Iberian thermal lows on fires in Portugal, also by the lagged correlation method.

The present paper discusses sequentially: data and method; statistics of burnt area in central Portugal; Iberian thermal low occurrence; summer climate conditions; lagged crosscovariances; and finally the role of the Iberian thermal lows for wildland fires in Portugal.

\section{Data and method}

Three data series were used in the current study: European Centre for Medium-Range Weather Forecasts (ECMWF) Reanalysis (ERA40) data; fire activity as provided by the Portuguese General Directorate of Forestry Resources (DGRF); and Iberian daily thermal low occurrence based on ERA40 taken from Hoinka et al. (2007).

The atmospheric data were part of the ERA40 set covering the period 1958-2001 generated by the ECMWF Reanalysis Project (Uppala et al. 2005). Spherical harmonics of wind, height, pressure, temperature and humidity data were transformed such that they were available at a $1^{\circ} \times 1^{\circ}$ horizontal grid. In the vertical, we used pressure-level data at $1000,925,850,775$ and $500 \mathrm{hPa}$ as well as model level data for $\sim 10,100,500$ and $1000 \mathrm{~m}$ above ground level (AGL). All fields were available four times a day, but daily mean fields were considered, except, if necessary, fields at 1200 and 1800 hours UTC (Universal Time, Coordinated). One has to keep in mind that the horizontal resolution (spectral triangularly truncated at total wavenumber 159, T159) of the temporally homogeneous data series ERA40 is sufficient to resolve synoptic-scale features, but allows the resolution of local-scale features, e.g. land and sea breeze, only to a certain extent.

The wildland fire database consists of daily information on the number of forest and shrubland fires and burnt area (BA) by district. In total, there are 18 regional districts in Portugal (see e.g. Pereira et al. 2005, their fig. 1). In the following, the term 'wildfire' is used for the sum of forest and shrubland fires. Mean annual BA of more than 8000 ha were observed in the following districts of central Portugal: Viseu, Guarda, Coimbra and Castelo Branco for the period 1980-2001. These districts have had the highest damage among all 18 Portuguese districts and are the regions with the highest fire weather risk (Viegas et al. 2004). In the present study, we concentrated on the belt between Spain and the coast, meridionally roughly limited by the rivers Douro and Tejo. This zonal belt includes additionally the district of Aveiro. In these five regions, the averaged annual total amount of BA was $\sim 51 \times 10^{3}$ ha, an area of wildland that was destroyed by $\sim 4100$ fires. In the chosen districts occurred the major part of Portuguese wildfires (total number as well as for fires with $\mathrm{BA} \geq 500 \mathrm{ha}$ ). The peak season of wildfires is the 
Table 1. Statistics of forest-, shrubland- and wildfires in central Portugal (five districts) and in all of Portugal (18 districts $^{A}$ ) between 1980 and 2001 (June-September)

BA, burnt area in ha; standard deviation, $\sigma$

\begin{tabular}{|c|c|c|c|c|c|}
\hline Data & & Sample days & Fire events $(\%)$ & $\overline{\mathrm{BA}}(\mathrm{ha})$ & $\sigma(\mathrm{ha})$ \\
\hline \multirow[t]{4}{*}{ Forest fire } & $\mathrm{BA}=0$ & 427 & 1.0 & 0 & 0 \\
\hline & $\mathrm{BA} \neq 0$ & 2257 & 99.0 & 237 & 876 \\
\hline & $\mathrm{BA} \geq 500$ & 215 & 17.8 & 1937 & 2188 \\
\hline & $\mathrm{BA} \geq 1000$ & 125 & 11.2 & 2825 & 2519 \\
\hline \multirow[t]{4}{*}{ Shrubland fire } & $\mathrm{BA}=0$ & 356 & 0.4 & 0 & 0 \\
\hline & $\mathrm{BA} \neq 0$ & 2328 & 99.6 & 223 & 491 \\
\hline & $\mathrm{BA} \geq 500$ & 293 & 27.7 & 1235 & 814 \\
\hline & $\mathrm{BA} \geq 1000$ & 140 & 14.6 & 1797 & 871 \\
\hline \multirow[t]{4}{*}{ Wildfire } & $\mathrm{BA}=0$ & 280 & 0.1 & 0 & 0 \\
\hline & $\mathrm{BA} \neq 0$ & 2404 & 99.9 & 438 & 1159 \\
\hline & $\mathrm{BA} \geq 500$ & 449 & 37.8 & 1985 & 2083 \\
\hline & $\mathrm{BA} \geq 1000$ & 267 & 24.6 & 2785 & 283 \\
\hline \multirow[t]{2}{*}{ Wildfire $^{\mathrm{A}}$} & $\mathrm{BA}=0$ & 108 & $\sim 0$ & 0 & 0 \\
\hline & $\mathrm{BA} \neq 0$ & 2576 & $\sim 100$ & 729 & 1679 \\
\hline
\end{tabular}

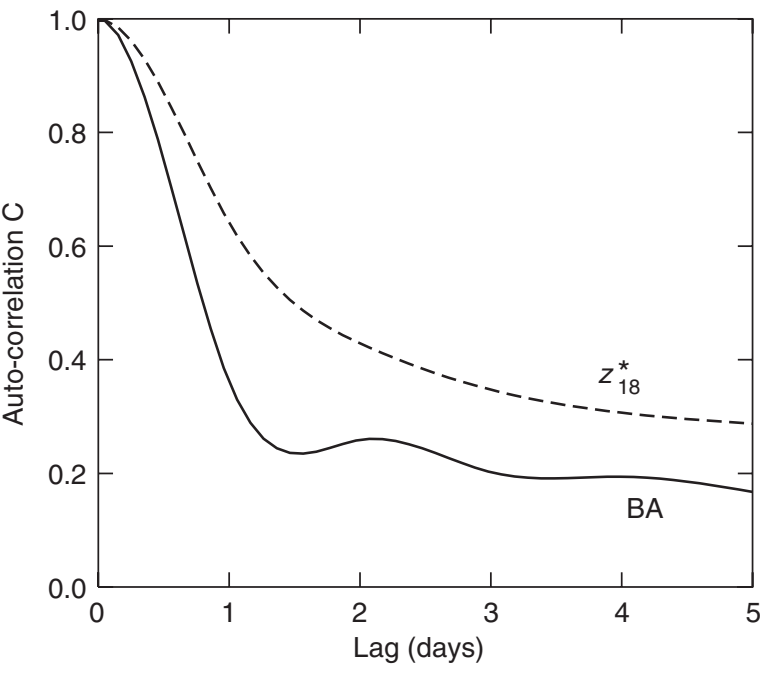

Fig. 2. Auto-correlation of burnt area, $B A, C(B A, B A \mid \tau)$ and of average cross-coast height differences, $z_{18}^{*}, \mathrm{C}\left(z_{18}^{*}, z_{18}^{*} \mid \tau\right)$ as function of lag.

period between June and September (JJAS) (Fig. 1). Because $\sim 93 \%$ of the annual BA was registered during these months, we restricted ourselves to this period. One has to keep in mind that the available time series of wildland fires has its limitations.

Statistics indicate that $97 \%$ of wildland fire ignitions in Portugal were due to human impacts: $37 \%$ due to arson, $28 \%$ negligence, $3 \%$ natural causes and $32 \%$ unknown causes (APIF 2005). Thus $97 \%$ of the wildland fires occur deliberately or carelessly. This suggests that the remaining 3\% are due to lightning. Clearly, the available wildfire statistics are useless for an adequate distinction between incendiaries and naturally-caused ignition. Nevertheless, in both cases, the local conditions of temperature, humidity and wind must be adequate to allow large fires resulting in an extended BA. 'Unfavorable' conditions for wildfires, even those started by incendiaries, are not very successful in forcing an extended fire. The reason for considering amounts of BA instead of number of fires is that the cause of fire starts does not play a key role for the BA. Additionally, a significant statistical relationship has been established between burnt area, weather and the fire weather risk, explaining $\sim 60$ to $80 \%$ of the variance for area burned depending on the district (Carvalho et al. 2008). In this respect, the time series of BA is an adequate indicator for days where favorable atmospheric conditions dominate over the IP. Obviously, this kind of time series is not optimal; however, at present an alternative approach does not exist.

The present study considered the daily BA integrated over the five abovementioned districts. To get a sufficiently strong regression signal, only days with a BA exceeding 500 ha were considered in the analysis. This somewhat arbitrary limit eliminates the smallest and least damaging fires, intense fires of limited extent, and most days with unfavorable wildfire conditions.

Finally, the series of Iberian thermal low occurrence were taken from Hoinka et al. (2007), containing the objectively determined occurrence of the Iberian thermal low based on ERA40 data. The related criteria can be found in Hoinka and Castro (2003). Fig. 1 shows that in summer, more than $50 \%$ of all days had thermal low events. However, this data series consists of daily information of yes or no related to a thermal low occurrence, and the lagged correlation analysis needs serial elements containing information on the strength of an event or parameter. The thermal low's centre is usually found above the IP's centre, associated with remarkable surface pressure gradients at the periphery of the low that coincide roughly with the peninsula's coastal boundaries (Hoinka and Castro 2003). This surface pressure pattern was used to define a temporal series of a parameter characteristic for Iberian thermal lows. A criterion was applied where the across-coast differences in the $925-\mathrm{hPa}$ surface height between the inner and the peripheral region of the IP were determined (see criterion V in Hoinka and Castro (2003)). The averaged differences $\left(z^{*}\right)$ form the time series considered. The averaged height difference at 1800 hours UTC $\left(z_{18}^{*}\right)$ is most prominent for the thermal low occurrence because the daily minimum surface pressure in the IP's centre occurs at this time. 

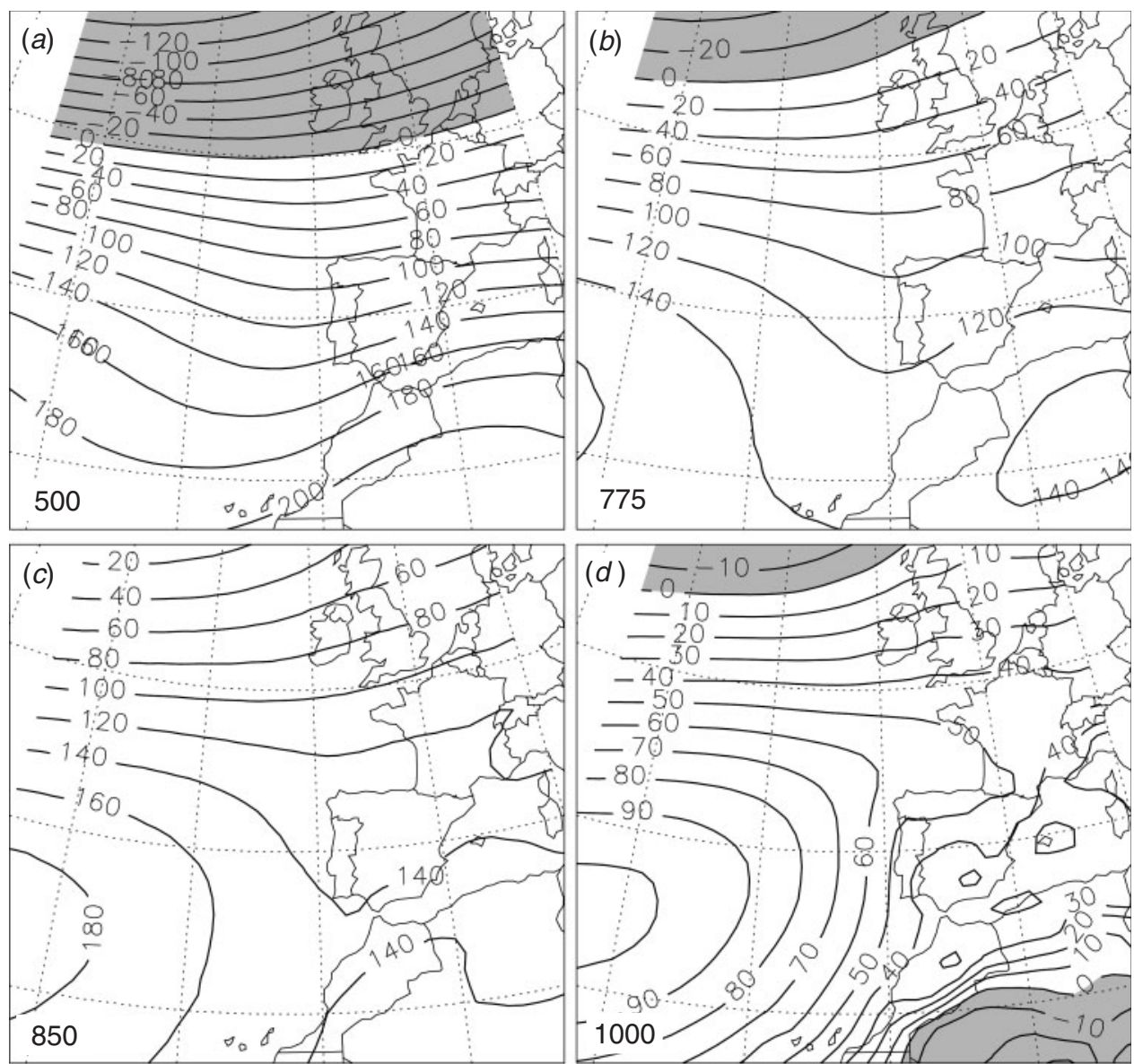

Fig. 3. Mean deviation of the height of pressure surfaces for June-September (1980-2001) taken from ERA40 data (see text): (a) height of $500 \mathrm{hPa}$ (reduced by $5700 \mathrm{~m}) ;(b) 775 \mathrm{hPa}(2200 \mathrm{~m}) ;(c) 850 \mathrm{hPa}(1400 \mathrm{~m}) ;(d) 1000 \mathrm{hPa}$ $(100 \mathrm{~m})$. The shaded areas indicate negative deviations.

All three data series - ERA40, amount of BA and occurrence of thermal low - were used to determine statistics for the period 1980-2001 by applying the lagged covariance method. See von Storch and Zwiers (1999) for a brief introduction to this technique. The period 1980-2001 was chosen according to the limit of the data series. There exists only a homogeneous data series of wildfires in Portugal starting from 1980. The statistics evaluated consist of covariances of BA in Portugal and grid point values of pertinent variables from ERA40. Let $C(b, c \mid \tau)$ denote the covariance of a variable $\mathrm{c}$ where $\mathrm{b}$ leads $\mathrm{c}$ with time lag $\tau$. For instance, all covariances $\mathrm{C}(\mathrm{BA}, \vec{v} \mid \tau)$ of the burnt area $\mathrm{BA}(\tau)$ series $(\tau$, time in days) with the components of the horizontal velocities vector $\vec{v}(\mathrm{x}, \mathrm{y}, \mathrm{z}, \mathrm{t})$ will be used to determine statistical flow features present during strong wildfires. To simplify the results, the crosscovariance fields were normalized by the standard deviation $(\sigma)$ so that the resulting fields could be interpreted in units of, for example, $\mathrm{m} \mathrm{s}^{-1}$ for the wind vector and correspondingly for the other meteorological parameters.

\section{Data statistics}

Statistics of the wildfire data series are given in Table 1. The entire sample of days of JJAS 1980-2001 was 2684 days. The statistics for the wildfires series show 2404 days with some $\mathrm{BA}, 449$ days with $\mathrm{BA} \geq 500$ ha and, for conflagrations events resulting in a $\mathrm{BA} \geq 1000 \mathrm{ha}, 267$ days were determined. The original time series of wildfires, as provided by the DGRF, contains also days with fire occurrences but no account of BA: 280 days (101 fires) in the 5 districts and 108 days (76 fires) in all 18 districts. These might be limited fire events with limited or no forest or scrubland damage. The sample of forest fire days with $\mathrm{BA} \neq 0$ ha was slightly smaller than that for shrub fires, whereas the average BA was larger. The central Portuguese region showed approximately one-third of the 270453 wildfires of the entire continental Portugal (JJAS). In terms of spatial extension, the five districts, with $\sim 24000 \mathrm{~km}^{2}$, represent almost $27 \%$ of continental Portugal's surface. The mean daily BA was 729 ha (18 districts from all of Portugal) and 438 ha (five districts from central Portugal), which indicates that the main part of wildfire-related BA occurred in central Portugal. In the five districts, the observed daily maximum reached 19966 ha for forest fires and 10500 ha for shrubland fires. The maximum number of daily forest fire events was 226 .

In Portugal, large wildfires have a duration of a few days only (DGRF 2006), which seems to be corroborated by the BA autocorrelation decaying quickly after lag zero (Fig. 2). However, the 

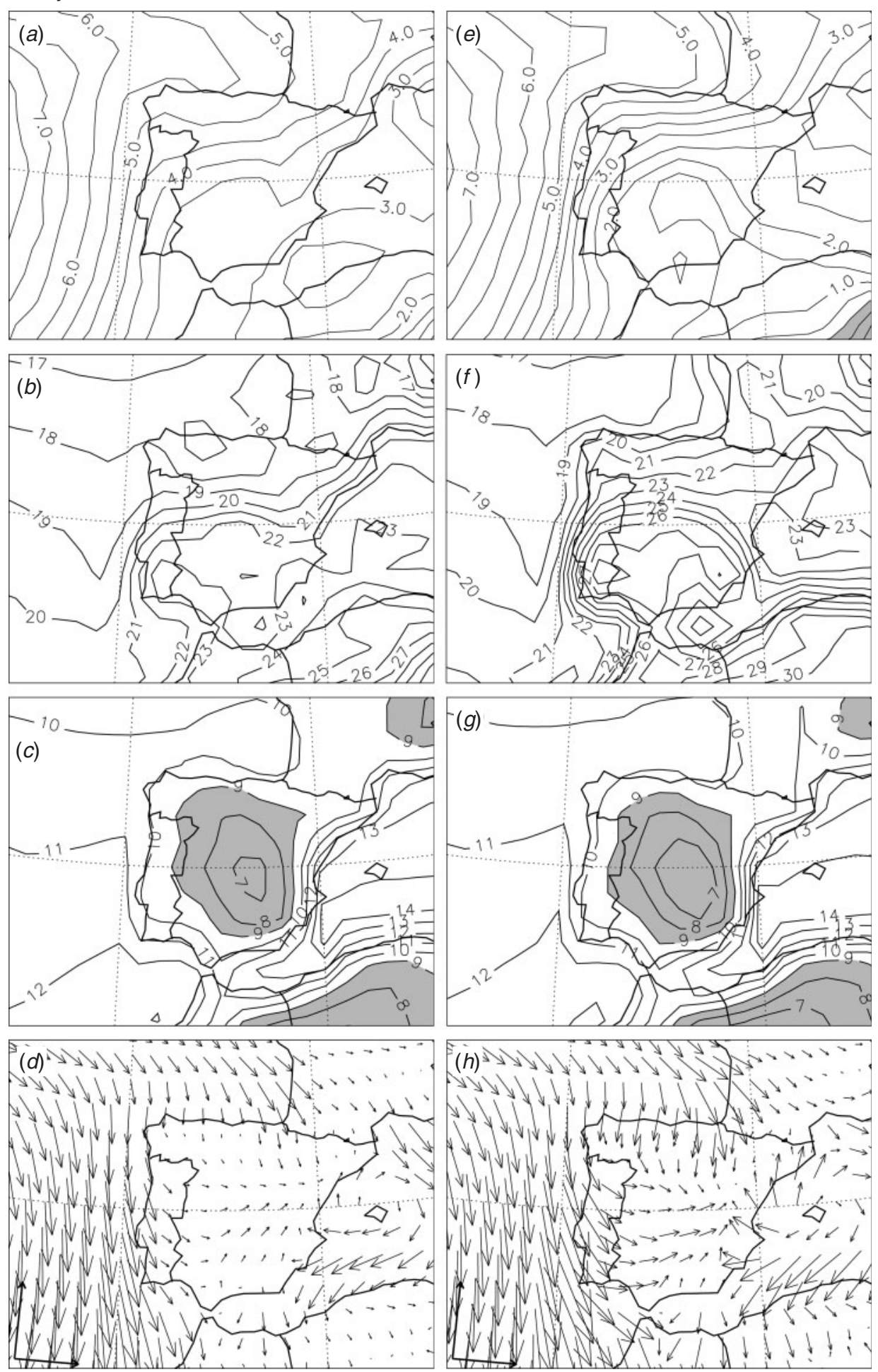

Fig. 4. Daily averages (left column) and 1800 hours UTC mean (right column) of mean sea level pressure (MSLP) and meteorological parameters at $10 \mathrm{~m}$ above ground level (AGL) for June-September (JJAS, 19802001) from ERA40 data (see text): $(a, e)$ MSLP (in hPa; reduced by $1013 \mathrm{hPa}) ;(b, f)$ temperature $\left({ }^{\circ} \mathrm{C}\right) ;(c, g)$ specific humidity averaged over the lowest $100 \mathrm{~m}$ above ground $\left(\mathrm{g} \mathrm{kg}^{-1}\right)$; and $(d, h)$ wind. The wind vector at the lower left edge indicates $5 \mathrm{~m} \mathrm{~s}^{-1}$. The shaded area in $(c, g)$ indicates areas with humidity lower than $9 \mathrm{~g} \mathrm{~kg}^{-1}$ in order to emphasize the Central Iberian minimum. 


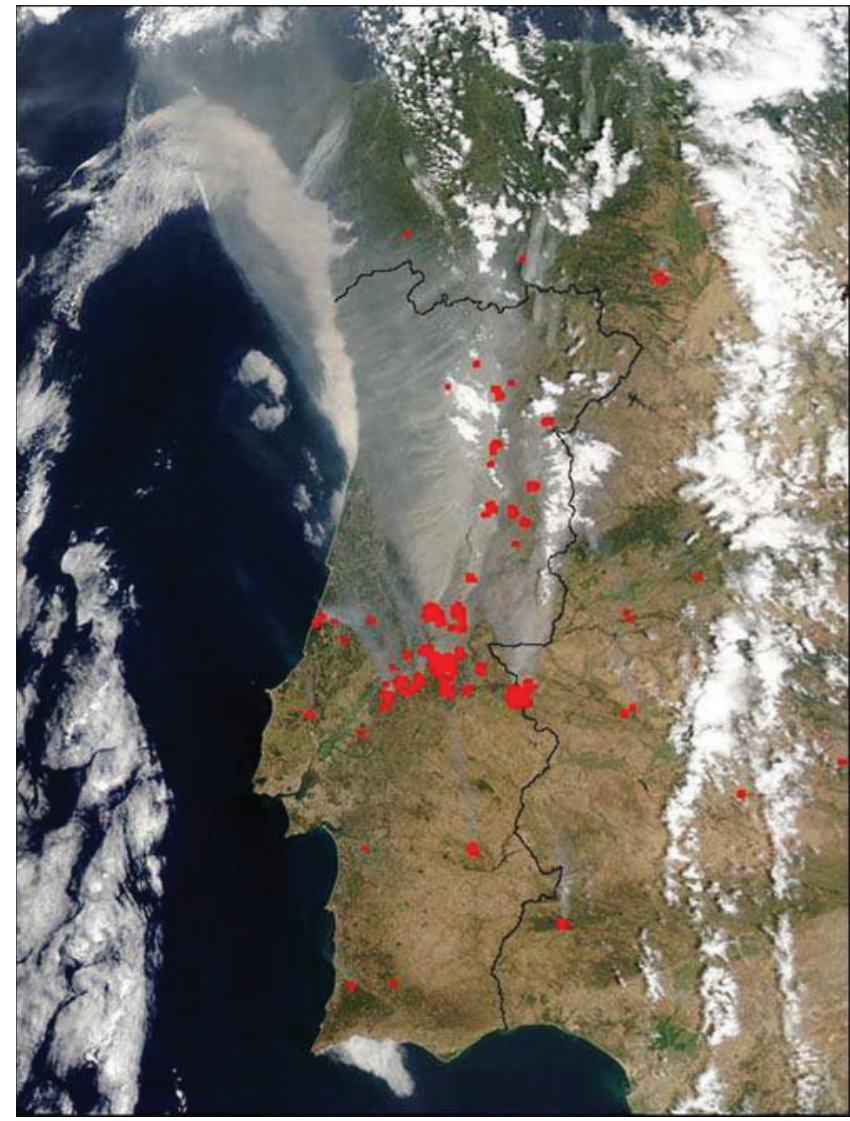

Fig. 5. Satellite image of 2 August 2003. The red spots indicate forest fires By courtesy of Zentrum für satellitengestützte Kriseninformation (ZKI) of the Deutsches Zentrum für Luft- und Raumfahrt (DLR) (Oberpfaffenhofen, Germany).

interpretation of this correlation is more complicated because the correlation depends not only on the fire duration but also on the number of fires. The lags are restricted to the interval $|\tau| \leq 5$ days because the majority of wildfires are short-lived and covariances are small for $\tau$ beyond 5 days. Fig. 2 shows also the autocorrelation of the averaged height differences $z_{18}^{*}$ characteristic of thermal lows as a function of time lag $\tau$. There are significant positive auto-correlations of up to 2 days for the occurrence of a central IP pressure minimum. The auto-correlation shows a weaker decay than that determined for BA, indicating the longer duration of thermal low events.

\section{Summer climate}

The climate of the Mediterranean is characterized by mild winters and warm, dry summers (Conrad 1943). It is well known that the particular wind conditions that dominate the fire regime are short-term meteorological extremes that are not strongly related to monthly or seasonal mean climate variations. Nevertheless, at first the climatic state of the extended summer period (JJAS) is briefly discussed, showing summertime statistics that provide in general favorable conditions for wildfires. Only selected days of this sample are characterized by very hot, dry and windy conditions being highly effective in enhancing or supporting wildfires.

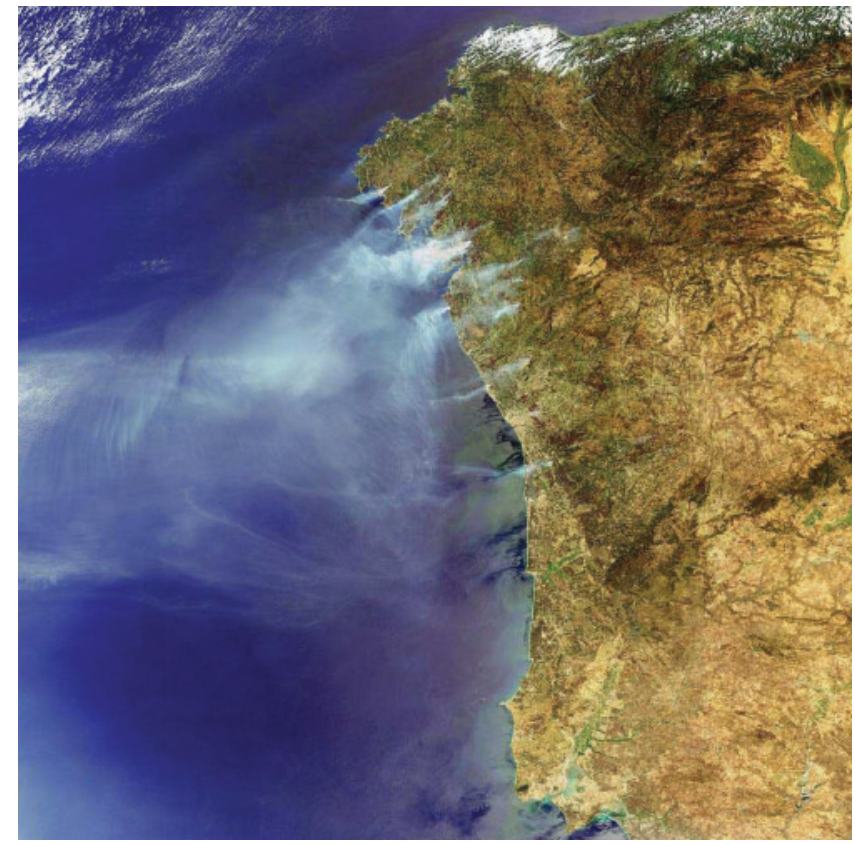

Fig. 6. Satellite image of 9 August 2006 at 1108 hours UTC. Courtesy of European Space Agency (ESA)

The summertime climate shows the north-easterly extension of the synoptic-scale high-pressure ridge of the Azores (Fig. 3). This feature is apparent from the surface up to the $850-\mathrm{hPa}$ level (Fig. $3 c, d$ ). The imbedded thermal low structure above the IP as well as the northern part of the Saharan thermal low are clearly apparent up to the $925-\mathrm{hPa}$ level (not shown). At $775 \mathrm{hPa}$, a remarkable trough is located at the western rim of Europe, which weakens strongly with increasing height.

The situation close to the surface at $10 \mathrm{~m}$ is given in Fig. 4, showing the daily averages (JJAS). This also includes the mean sea level pressure (MSLP). The left column (Fig. $4 a-d$ ) shows the daily means and the right one (Fig. $4 e-h$ ) the averages at 1800 hours UTC.

Because the thermal low peak time is 1800 hours UTC (Fig. 4e), it appears only weakly in the daily averaged MSLP pattern (Fig. 4a) in the southern part of the IP. The averaged temperature (Fig. $4 b$ ) rises up to $23^{\circ} \mathrm{C}$ above the IP, reaching at 1800 hours UTC values of up to $28^{\circ} \mathrm{C}$ (Fig. $4 f$ ). The specific humidity (Fig. $4 c, g$ ) of the surface-based air decreases to less than $7 \mathrm{~g} \mathrm{~kg}^{-1}$ where the spatial extension is larger at 1800 hours UTC. The wind field (Fig. $4 d, h$ ) shows in general a northerly flow above the Atlantic Ocean, which turns to a north-westerly flow above Portugal. Above eastern Spain, this flow turns to southerly directions with weak wind speeds of $\sim 1 \mathrm{~m} \mathrm{~s}^{-1}$. Above land, the wind speeds are larger at 1800 hours UTC.

Recently available high-resolution satellite data show significant spreading of fire plumes, indicating the prevailing flow. The smoke plumes detected by satellites indicate a flow quite different to the averaged summertime northerly flow. Two wildfire cases are discussed here to illustrate this phenomenon.

Fig. 5 displays strong fires north of Lisbon in the districts of Santarém, Coimbra and Castelo Branco on 2 August 2003. 


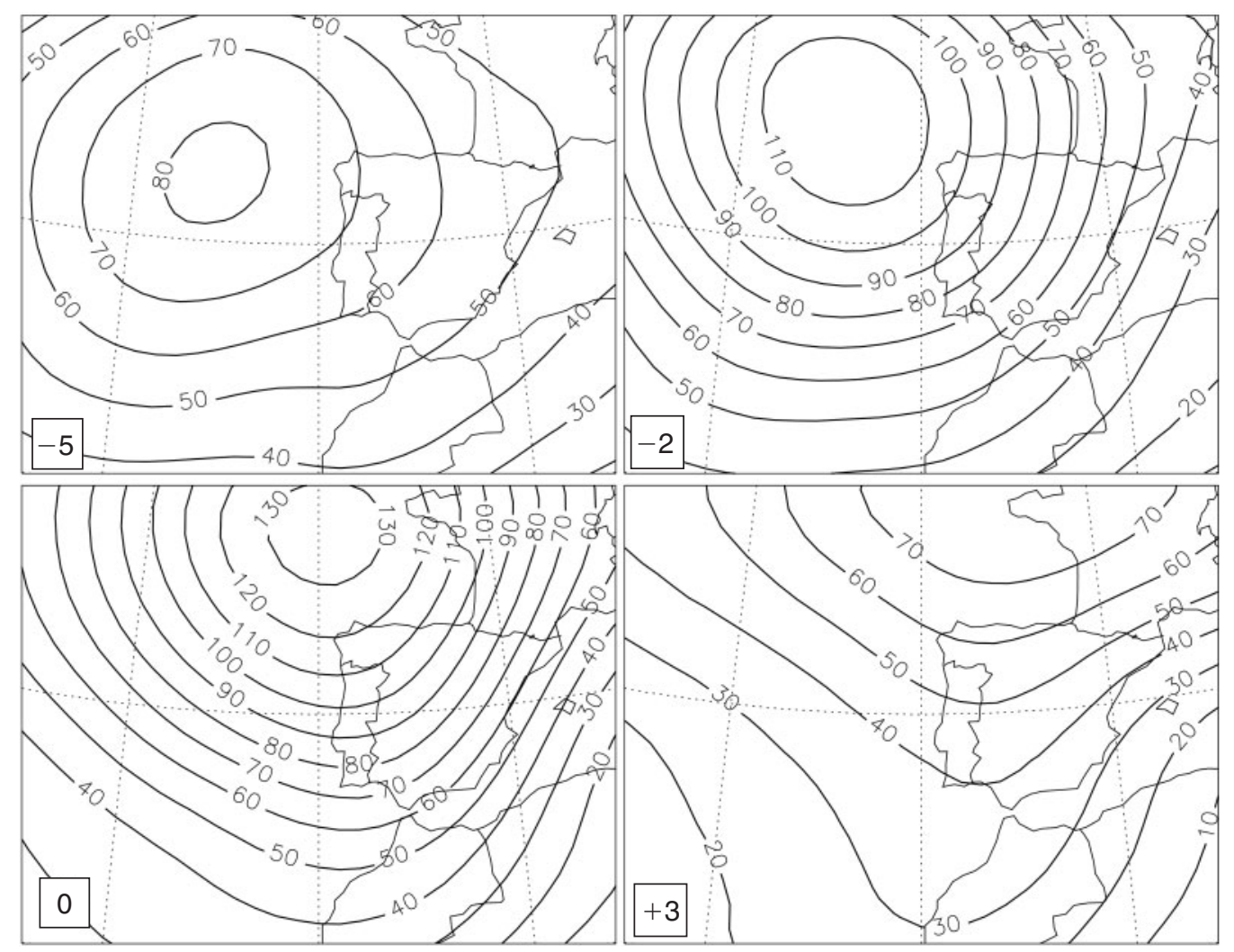

Fig. 7. Cross-covariances $\mathrm{C}(\mathrm{BA}, \mathrm{z} 500 \mid \tau)$ of the normalized burnt area (BA) in central Portugal. The lag times (days) are indicated in the boxes. Units in $\mathrm{m}$.

During the preceding days, a weak cyclone developed over the Western Atlantic near the south-western edge of the IP. An occlusion approached the IP from the south-west with a southerly flow at its leading edge lasting for several days. This prefrontal northerly advection transported hot air from the African continent towards the IP, strongly enhancing the fire weather risk and supporting the spread of wildfires. Ramos and Ventura (1992) identified an elongated thermal low pressure system extending from the Sahara as one of the synoptic situations in which fire risk was found to be extreme due to the northerly advection of warm, dry air from northern Africa. However, the northerly advection on 2 August is of prefrontal character. This synoptic situation is a rare one because the typical summertime weather situation is characterized by weak horizontal pressure and temperature gradients.

A typical summertime synoptic situation occurred on 9 August 2006 (Fig. 6), forcing wildfire plumes above Galicia (Spain) and northern Portugal. It is apparent that the plumes indicate a flow from the east transporting polluted material to the Atlantic Ocean. The plume dispersion is clearly visible, indicating also a northerly flow component above the Ocean. This situation is characterized by a homogeneous synoptic-scale environment with weak horizontal gradients. It is not obvious per se that there exists an organized easterly flow.

The summertime climatological wind statistics show neither an easterly nor a southerly flow above the IP. Both situations indicate that the northerly and westerly spreading of wildfire plumes seen in Figs 5 and 6 represent departures from the prevailing summertime climate. Based on data of a 2-year period, Lourenço (1988) already pointed out that surface easterly winds dominate during fire events in Portugal. Therefore, in the following, the method of lagged covariances was used to determine the synoptic-scale circulation during wildfires in Portugal.

\section{Results of the cross-covariance analysis}

In the following, the time series of BA were correlated with pressure, geopotential height, temperature, humidity and wind from the ERA40 data. The latter three are seen to be the key atmospheric parameters for the starting of wildfire and its evolution.

\section{Pressure and height}

Pereira et al. (2005) determined composite fields of the height of 500- and 850-hPa surface. These composite fields consisted of days of highest values of BA in Portugal. At $500 \mathrm{hPa}$, a weak ridge of high pressure was determined above the IP associated with an anomaly north of the IP. Other studies (e.g. Skinner et al. 2002) have already established significant correlation between the 500-hPa surface and the BA. Based on the lagged covariance method, the development of the pressure anomaly can be studied for different lag times. Fig. 7 exhibits the evolution of the covariance field $\mathrm{C}(\mathrm{BA}, \mathrm{z} 500 \mid \tau)$ for the height of the $500-\mathrm{hPa}$ surface (z500).

A positive covariance anomaly appears to the west of the IP at $\tau=-5$ days and moves then towards Brittany in France, where 

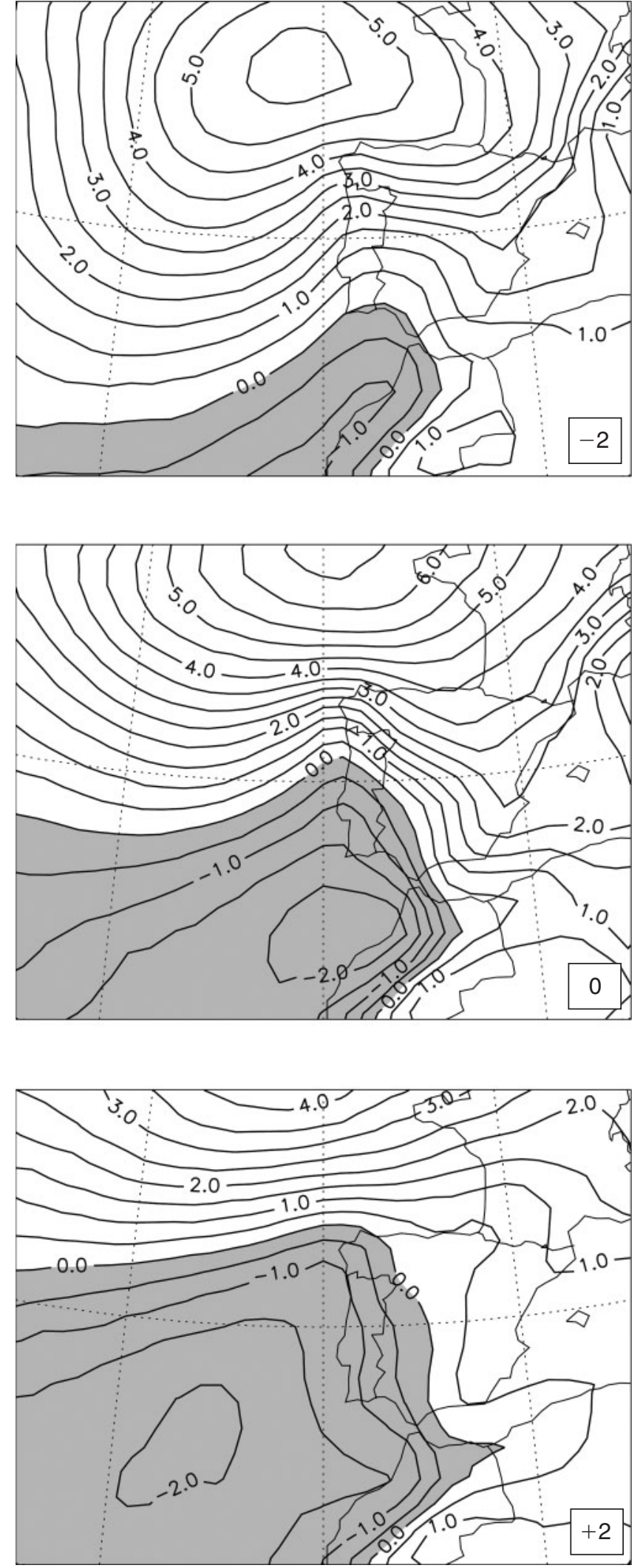

Fig. 8. Cross-covariance, $\mathrm{C}(\mathrm{BA}, \mathrm{MSLP} \mid \tau)$ of the normalized BA in central Portugal. The lag times in days appear in the lower right-hand corner. Units in $\mathrm{hPa}$; negative covariances are shaded. it arrives at $\tau=0$ days. The amplitude of the anomaly is stronger in advance of the event, reaching more than $80 \mathrm{~m}$ ( $\tau=-5$ days), than after the event, when it decreases more rapidly towards $50 \mathrm{~m}$ at $\tau=+5$ days. The maximum anomaly occurs at lag equal 0 with more than $130 \mathrm{~m}$. Applying a time series considering all wildfires with $\mathrm{BA} \neq 0$ ha, the evolution is comparable but the maximum reaches only $25 \mathrm{~m}$ at $\tau=0$ days. However, considering a time series where no fires are accepted except those with BA > 1000 ha, the peak anomaly reaches more than $200 \mathrm{~m}$. This indicates that the correlation is stronger for the days with larger BA.

Alcoforado and de Almeida (1993) pointed out that 41\% of all fires occurred imbedded in an Atlantic anti-cyclone and 24\% of these anti-cyclonic events extended towards the north-east. In the latter case, the number of fires was significantly larger. Of course, these results have been found also by others (e.g. Skinner et al. 2002), but here the temporal evolution from the pre- to the post-event phase is determined and described.

The MSLP fields (Fig. 8) also show a positive covariance anomaly over the Atlantic Ocean. There is no tilt in the vertical axis of the high pressure centre at the surface and the geopotential maximum at the $500-\mathrm{hPa}$ level, indicating that the synopticscale system is stationary. It is interesting to note that there is an increase with height in the positive covariance anomaly. At the surface, the pressure maximum amounts to $6.7 \mathrm{hPa}$, whereas at $500 \mathrm{hPa}$, this increases to $9.2 \mathrm{hPa}$, which is equivalent to the maximum height of $\sim 135 \mathrm{~m}$. An explanation for the vertical increase cannot be given here. With increasing lag time, a negative cross-covariance anomaly develops, stretching from the southern Atlantic towards the south-western edge of the IP. This negative anomaly reaches its maximum between $\tau=1$ day and $\tau=2$ days and then it falls back towards the Atlantic Ocean. The isolines of pressure are squeezed between the northerly positive and the southerly negative covariance anomaly over the western IP coast, particularly over northern Portugal and Galicia in Spain. This leads to an enhanced ageostrophic flow.

\section{Temperature and humidity}

Fig. 9 shows the covariance field $\mathrm{C}(\mathrm{BA}, \mathrm{T} \mid \tau)$ of $\mathrm{BA}$ with the mean daily 10-m temperature. Viegas et al. (2006) pointed out that wildfires are preceded by several days with meteorological conditions of enhanced fire weather risk. This is clearly reflected in the covariance fields. At lag $=-5$ days, there is already a strong signal of high temperature of up to $4 \mathrm{~K}$. This increases further up to $7 \mathrm{~K}$ at $\tau=0$ days and decreases rapidly after the event. The comparison of $\tau=-5$ days with $\tau=+5$ days fields shows that in advance of the event, a strong temperature configuration is apparent. At $\tau=0$ days, the temperature anomaly is concentrated on locations in central Portugal and the Spanish Extremadura region. Considering the 1800 hours UTC fields instead of the daily averages, the peak value at $\tau=0$ days increases up to $8 \mathrm{~K}$. The general pattern remains the same.

The daily maximum and minimum temperatures at $10 \mathrm{~m}$ show the strongest signal at $\tau=0$ days, where the maximum covariance anomaly of $4 \mathrm{~K}$ for $\mathrm{T}_{\min }$ and of $8 \mathrm{~K}$ for $\mathrm{T}_{\max }$ are found (Fig. 10). After the event, the maximum temperatures decrease faster than the minimum temperatures. Consequently, a separate regression of time series of $\mathrm{T}_{\max }$ and $\mathrm{T}_{\min }$ shows that the daily 


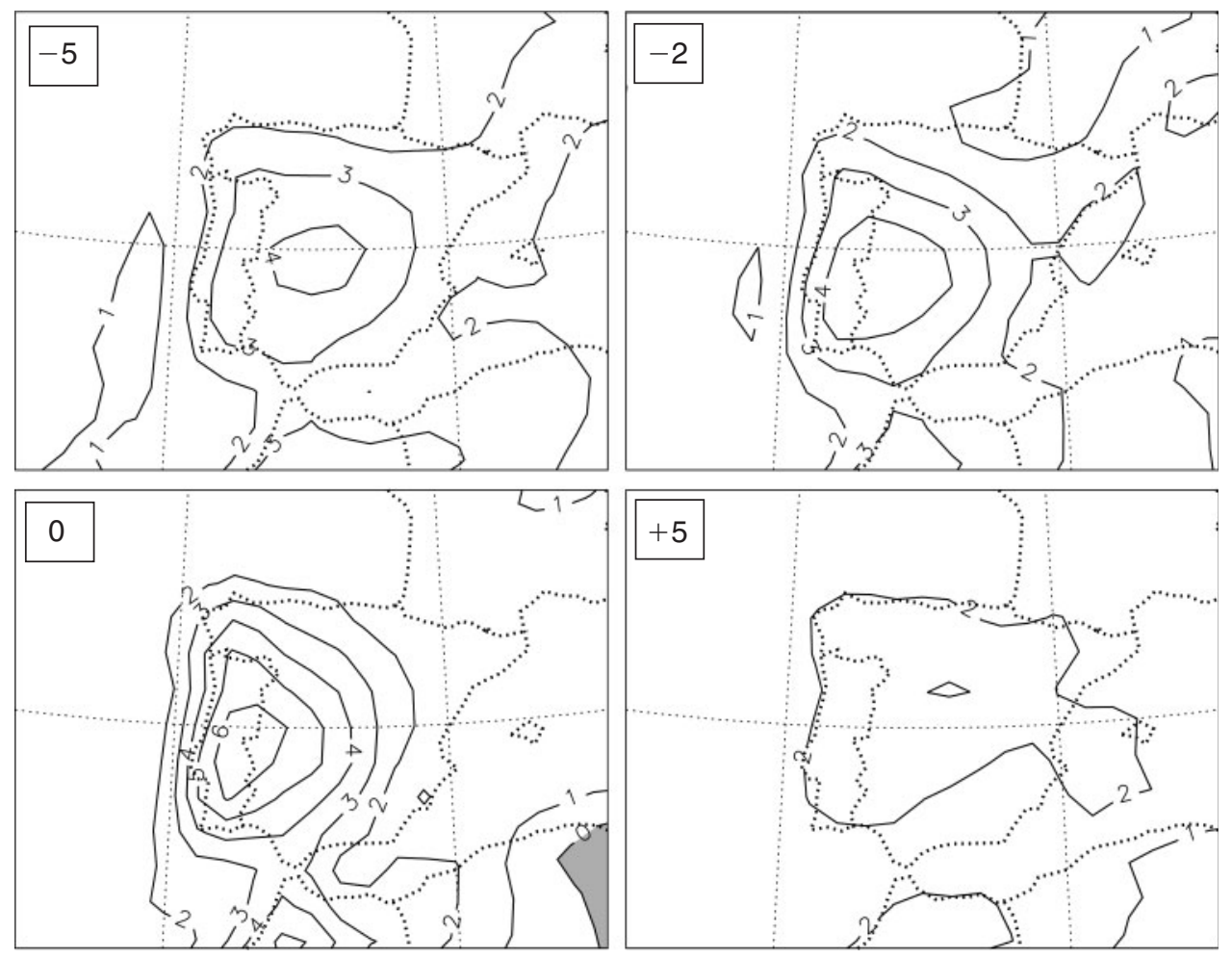

Fig. 9. Cross-covariance $\mathrm{C}(\mathrm{BA}, \mathrm{T} \mid \tau)$ of the normalized $\mathrm{BA}$ in central Portugal. The lag times in days are indicated. Units in $\mathrm{K}$.

temperature spread (difference between maximum and minimum temperature) has its maximum at lag zero $(4 \mathrm{~K})$, being slightly weaker in the pre-event and very weak in the post-event phase. The maximum covariance anomaly is located in the same region as found for the daily averaged temperature, as well as for the 1200 and 1800 hours UTC ones.

The surface humidity and the humidity content of the overlying air are two of the key parameters for wildfires. Fig. 11 shows the covariance field $\mathrm{C}(\mathrm{BA}, \mathrm{q} \mid \tau)$ of BA with the atmospheric specific humidity (q), at 1800 hours UTC. Here $q$ is the vertical mean specific humidity over the lowest $100 \mathrm{~m}$ above ground, representing a reasonable measure of the atmospheric humidity of the boundary layer. An arbitrary limit of $9 \mathrm{~g} \mathrm{~kg}^{-1}$ is chosen in Fig. 11 to emphasize the Central Iberian minimum. The peak negative covariance anomaly appears already 1 day before the event. This indicates that very low humidity exists 3 to 4 days before the event. After $\tau=0$ days, the anomaly dissolves rapidly.

\section{Wind}

Local winds at the fire-scale can be either strongly modified or even solely produced by the fire. However, synoptic- to mesoscale low-level wind can play a dominating role independently from the fire. In Fig. 12, the wind is given at $10 \mathrm{~m} \mathrm{AGL,} 1000 \mathrm{~m}$ $\mathrm{AGL}$ and at $850 \mathrm{hPa}$ for various lags. This figure can be seen as the typical wind field to be expected for days with large BA with an amplitude of $1 \sigma$. At $10 \mathrm{~m}$, the wind apparently follows the coastline at the western and southern edge of the peninsula. An ageostrophic wind exists owing to the strong surface pressure gradients as apparent in Fig. 8. Above Portugal at $\tau=-2$ days, the flow comes from the north. At $\tau=0$ days, the wind turns to north- and south-easterlies, and at $\tau=+2$ days, a south-easterly flow dominates. This feature becomes much more evident at $1000 \mathrm{~m}$ AGL with an easterly flow at $\tau=0$ days and southeasterlies at $\tau=+2$ days. This pattern strengthens at the $850-\mathrm{hPa}$ surface and the effect of flowing around the IP is weakly apparent at $\tau=+2$ days. At lower levels, this flow-around effect is much more evident where, in particular, the eastern and southern edge of the peninsula seem to 'force' the flow.

The covariance field of the wind (Fig. 12) clearly explains the plume's spreading observed on 9 August 2006 (Fig. 6). Moreover, the spreading plume enters a zone of divergence above the Atlantic Ocean. This is nicely corroborated by the wind field at $\tau=0$ days for $1000 \mathrm{~m}$ AGL (Fig. 12). The calculations indicate the most probable statistical wind structure during the occurrence of wildfires with large BA in Portugal. The veering of the surface wind from the east to the south was recently found by Trigo et al. (2006) for the exceptional fire event of the beginning of August 2003.

A further corroboration of the covariance fields of wind (Fig. 12) comes from surface wind measurements taken at Castelo Branco between 1985 and 1995, at 1200 and 1500 hours UTC (Fig. 13). The location of Castelo Branco is marked by a dot in the lower left hand panel of Fig. 12. Fig. 13 shows wind directional frequencies summarized over sectors of $30^{\circ}$.

For days without wildfires, a large frequency of $\sim 50 \%$ of the wind comes predominantly from the westerly sector (SW-NW). This is valid for both datasets: measured and analysed 

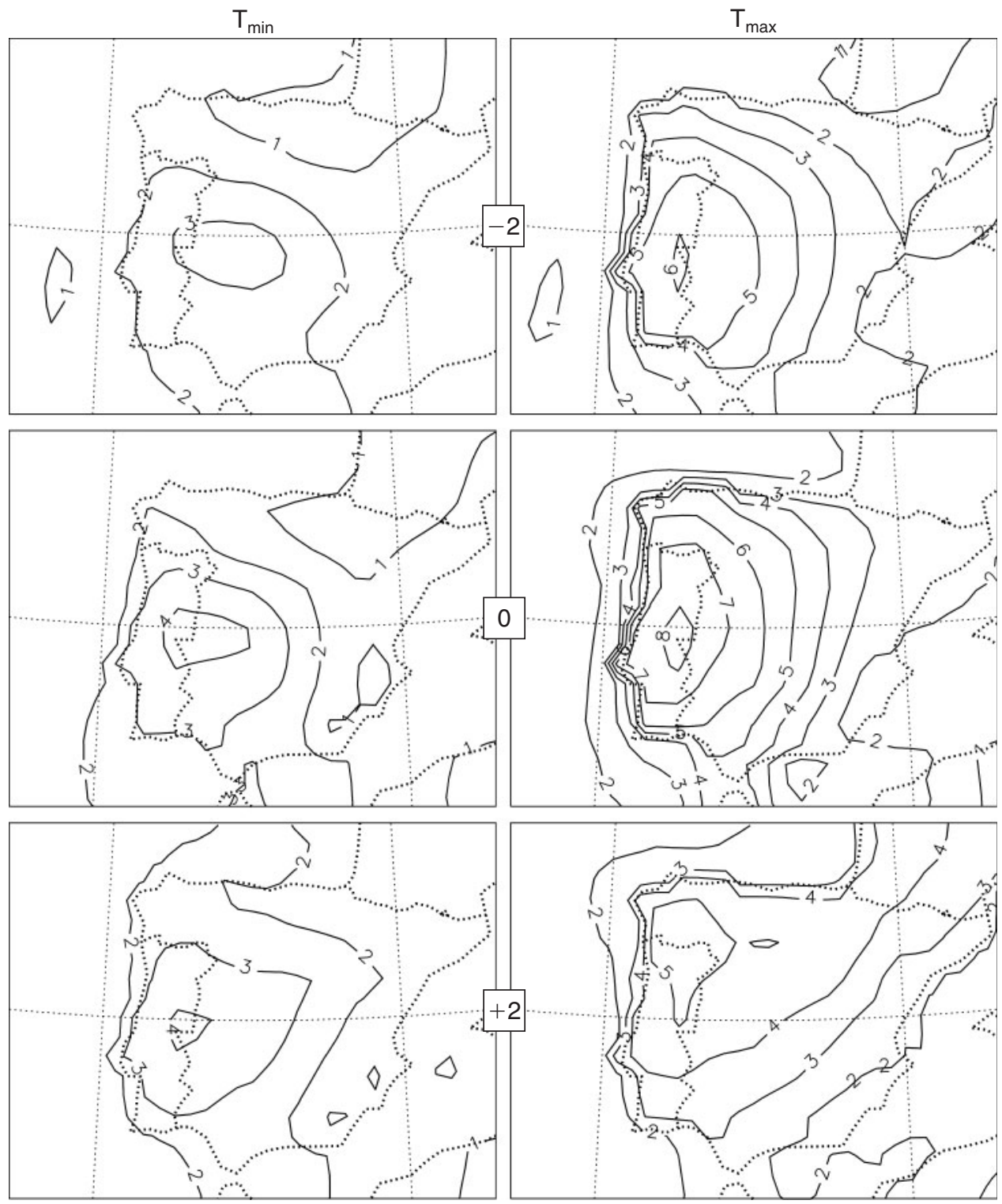

Fig. 10. Cross-covariance $C\left(B A, T_{\max } \mid \tau\right)$ (right panels) and $C\left(B A, T_{\min } \mid \tau\right)$ (left) of the normalized BA in central Portugal. The lag times in days are indicated in the boxes. Units in $\mathrm{K}$.

(ERA). It is apparent that the situation is quite different during wildfires. The most prominent sectors where the wind comes from are the eastern and the southern, both with a frequency of $13-14 \%$. Flow with an easterly component (between NE and SE) amounts to $\sim 30 \%$ and with a southerly one (SW-SE) to $\sim 25 \%$. Both dominant directions are represented by the two events demonstrated by satellite images (Figs 5 and 6 ).

The ERA40 data show a similar structure with dominant easterlies at 0600 hours UTC, which turn into south-westerlies until noon. The veering of the wind observed at Castelo Branco shows a comparable behaviour; however, the easterly flow dominates until noon and the veering round to the south-west occurs during the following hours. Note that Fig. 13 shows the wind of Castelo Branco at $10 \mathrm{~m}$ AGL and that of from ERA40 at $100 \mathrm{~m}$ AGL. One has to keep in mind that both sets of data can be compared only to a certain extent because they depend on the underlying orography. The wind roses of Castelo Branco show locally measured winds. The local character of the surface wind is also apparent in the study of Alcoforado and de Almeida (1993), investigating local flow conditions in the Portuguese Parque Natural da Arrábida (district of Lisbon). They showed that the main flow comes from northerly directions but shows weak easterly components. The ERA40 data give winds that are related to the smoothed ERA40 orography. This represents topographic features at a truncation of T159 and could be quite different to the real topography, particularly in unhomogeneous terrain. Thus ERA40 winds are representative for a larger scale (e.g. meso scale) than the locally observed $10 \mathrm{~m}$ winds. This could explain the differences determined between surface wind observations and ERA40 winds. 

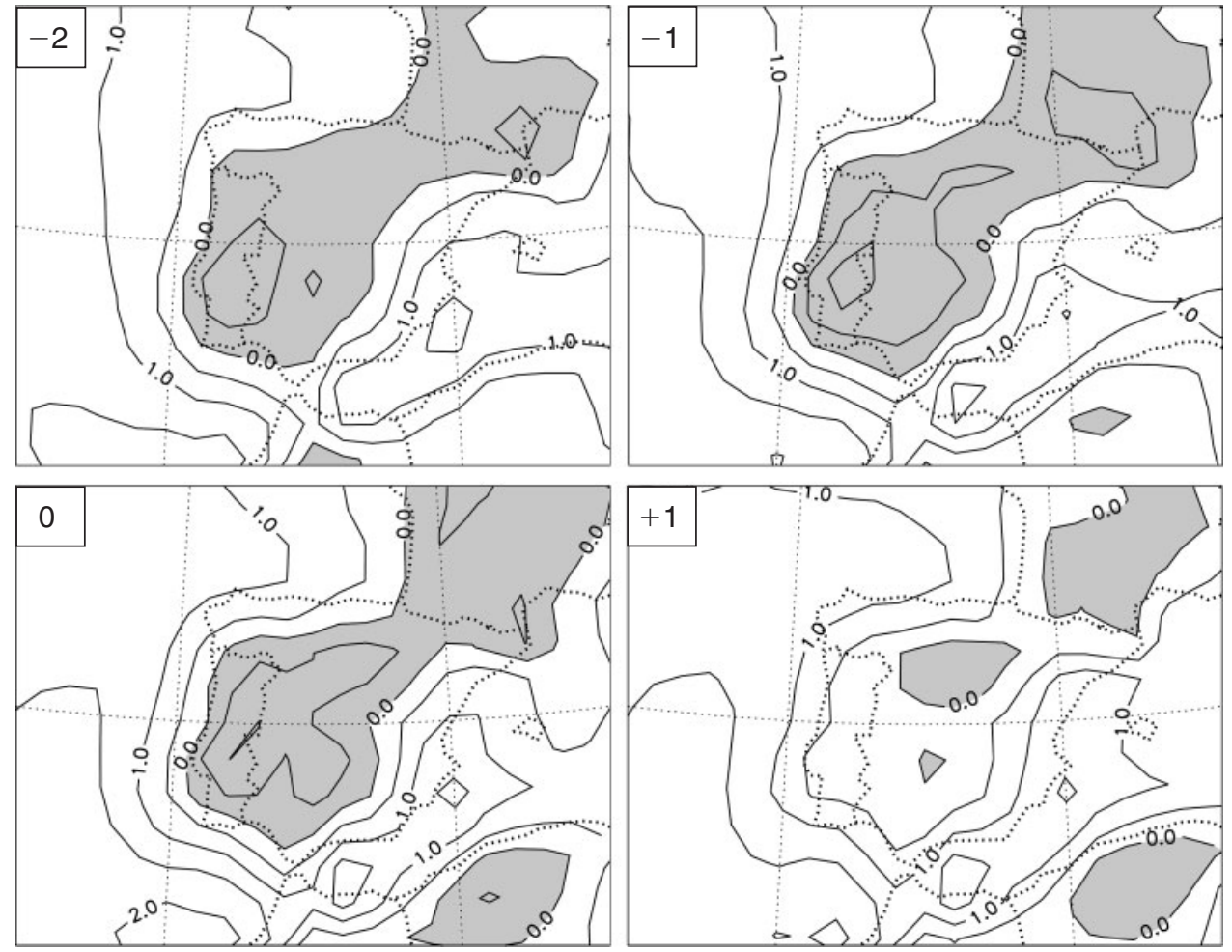

Fig. 11. Cross-covariance $C(B A, q \mid \tau)$ of the normalized $B A$ in central Portugal with the specific humidity (q) at 1800 hours UTC. Here q is humidity averaged over the lowest $100 \mathrm{~m}$ above ground. The lag times in days are indicated in the top left-hand corners. Units in $\mathrm{g} \mathrm{kg}^{-1}$; negative covariances are shaded.

\section{Wildfire and thermal low}

The thermal low is a shallow, non-frontal depression that forms above continental regions mostly during summer months because of the intense surface heating over land. It is classified as one of the important weather types in the Iberian summer climatology. Besides the extended Azores ridge of high pressure, Ramos and Ventura (1992) identified an elongated thermal low pressure extending from the Sahara as a synoptic pattern in which fire risk was found to be extreme. The occurrence of an Iberian thermal low is strongly related to its Saharan counterpart. Because summer is the peak season for both occurrence of Iberian thermal lows and large central Portugal BA (see Fig. 1), it is reasonable to investigate if there is a link between both parameters.

A correlation based on monthly averaged BA and monthly number of Iberian thermal low days shows that the number of thermal low days is highly correlated with the BA as well as the mean monthly $z_{18}^{*}$ and maximum $z_{18}^{*}$. This is evident from Fig. 1. At a 95\% confidence level, statistically significant Spearman correlations were obtained between the monthly BA and mean monthly $z_{18}^{*}(r=0.57)$ and the monthly number of thermal low days $(r=0.49)$. The correlations obtained were positive and significant, indicating a strong relationship between thermal low conditions and fire activity in Portugal.

Table 2 shows a combination of wildfire statistics with those of thermal lows for all summers (JJAS) of the period 19802001. The entire sample consists of 2684 days, which include 1328 days with a thermal low over the IP. For the chosen period, the averaged BAs are similar for days with and without thermal lows. Only, the $\sigma$ is larger in the latter case and the mean BA is larger for the non-thermal low sample. The reason for these weak differences must be seen in the fact that the usual summertime conditions are close to the thermal low conditions.

The cross-covariance function between BA and the occurrence of the thermal low $\left(z_{18}^{*}\right)$ given in Fig. 14 indicates that the peak amount of BA happens up to 3 days after the appearance of an Iberian thermal low. This lag suggests that a comparison of averaged values (Table 2) could not show significant differences between both events discussed here. But the lag suggests that the existing surface easterly flow in advance of wildfires transports heated air from the IP's centre towards central Portugal, supporting favorable wildfire conditions in this region.

\section{Summary and discussion}

Atmospheric conditions are one of the major factors of importance that enhance or even suppress disastrous consequences of wildland fires. In the present study, we discussed lagged regressions of ERA40 atmospheric fields with time series of BA registered in central Portugal for the period from 1980 to 2001. One has to keep in mind that regional differences in the wildland fire characteristics exist, as has been shown for various regions of Spain (Vásquez and Moreno 1995) and Portugal (Viegas et al. 2004, 2006). With this caveat in mind, it is possible to make some statements about the general pattern of weather-fire relationship, including the most likely weather pattern significant for the fire-prone regime of central Portugal. 
10 m AGL
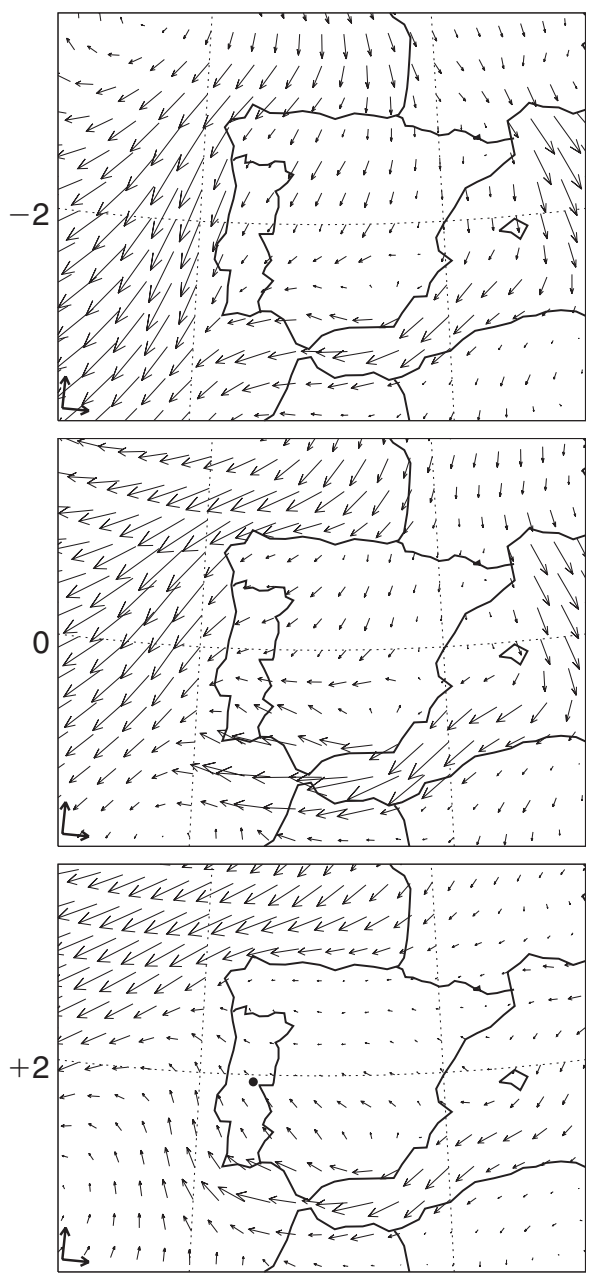

$1000 \mathrm{~m} \mathrm{AGL}$
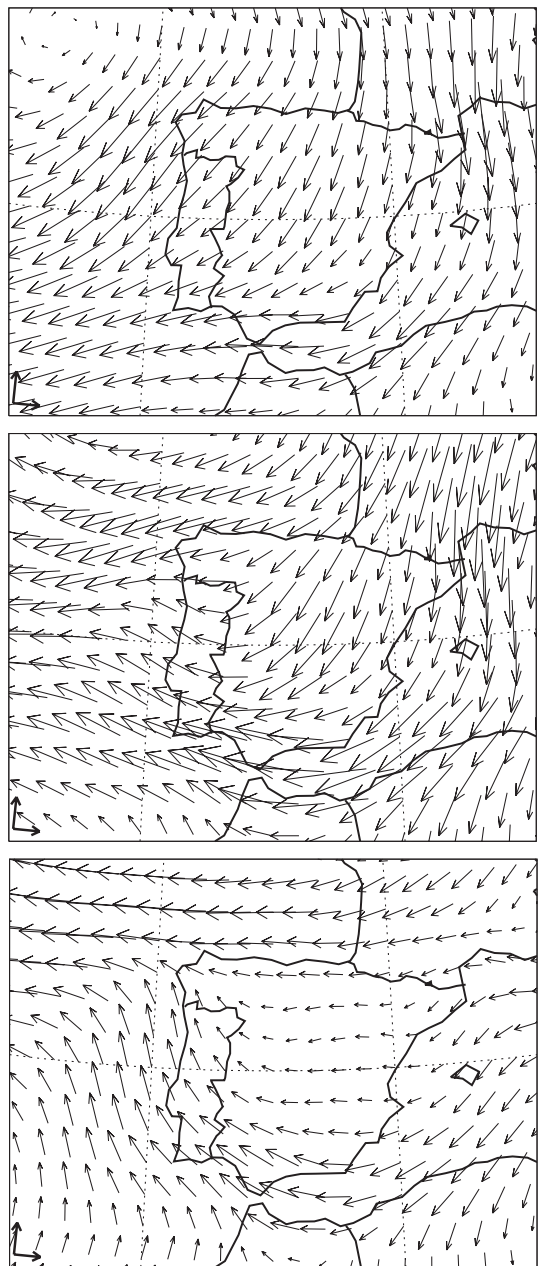

$850 \mathrm{hPa}$
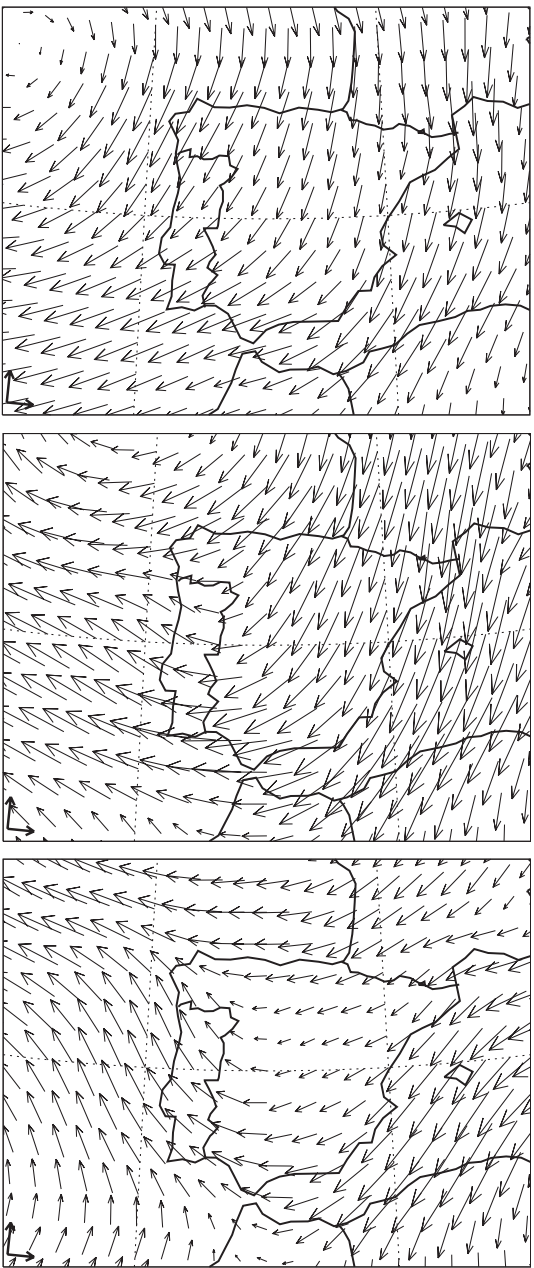

Fig. 12. Cross-covariance $C(B A, \vec{v} \mid \tau)$ of the normalized BA in central Portugal with winds at $10 \mathrm{~m}, 1000 \mathrm{~m}$ (both above ground level and at $850 \mathrm{hPa})$. The lag times in days are indicated at the left side margin. The arrows in the lower left hand corner indicate $2.5 \mathrm{~m} \mathrm{~s}^{-1}$. The dot in the lower left hand panel indicates the location of Castelo Branco.

During summer, the large-scale atmospheric circulation is steered by the Azores anti-cyclone, which is displaced towards its north-easterly position, producing northerly (north-easterly) winds that transport warm (dry) air to Portugal of maritime (continental) origin. In the lower troposphere, this circulation is usually reinforced at the meso-scale by the development of a thermal low, centred over the IP. This surface-based depression is notable up to $925 \mathrm{hPa}$. The mean summertime conditions of temperature and humidity are favorable for the ignition and spread of wildland fires. However, the averaged low-level surface flow structure explains neither the plume spread of wildland fires in Portugal as exhibited by satellite data nor the observations of firemen.

Lagged covariance fields of the height of 500-hPa surface with BA in central Portugal show a positive anomaly appearing to the west of the IP 5 days in advance of an event and moving towards Brittany in France where it arrives at lag time of zero days. A similar positive anomaly appears in the covariance field of the MSLP. There is no tilt in the vertical axis in the position of the high pressure centres, indicating stationarity. In the lower troposphere, there is a narrowing of the isobars along the western coast of the IP leading to an enhanced ageostrophic northerly flow.

In advance of fire events, the flow in the lowest $1000 \mathrm{~m}$ above ground comes from the north, turning to easterlies at lag time zero and finally coming from the south-east during the postevent phase. This flow evolution confirms the flow-dependent plume spread visible in satellite data. Surface wind statistics taken at Castelo Branco support these results. Up to 5 days in advance of an event, the temperature shows high values above central Portugal and the Spanish Extremadura region with weak increase during the pre-event phase. The temperature reaches its maximum at lag time of zero days and decreases rapidly after the event. A similar characteristic shows the specific humidity of the lowest $100 \mathrm{~m}$ AGL, with low magnitudes in advance, minimum at lag time of zero days and rapid increase after the event. The 


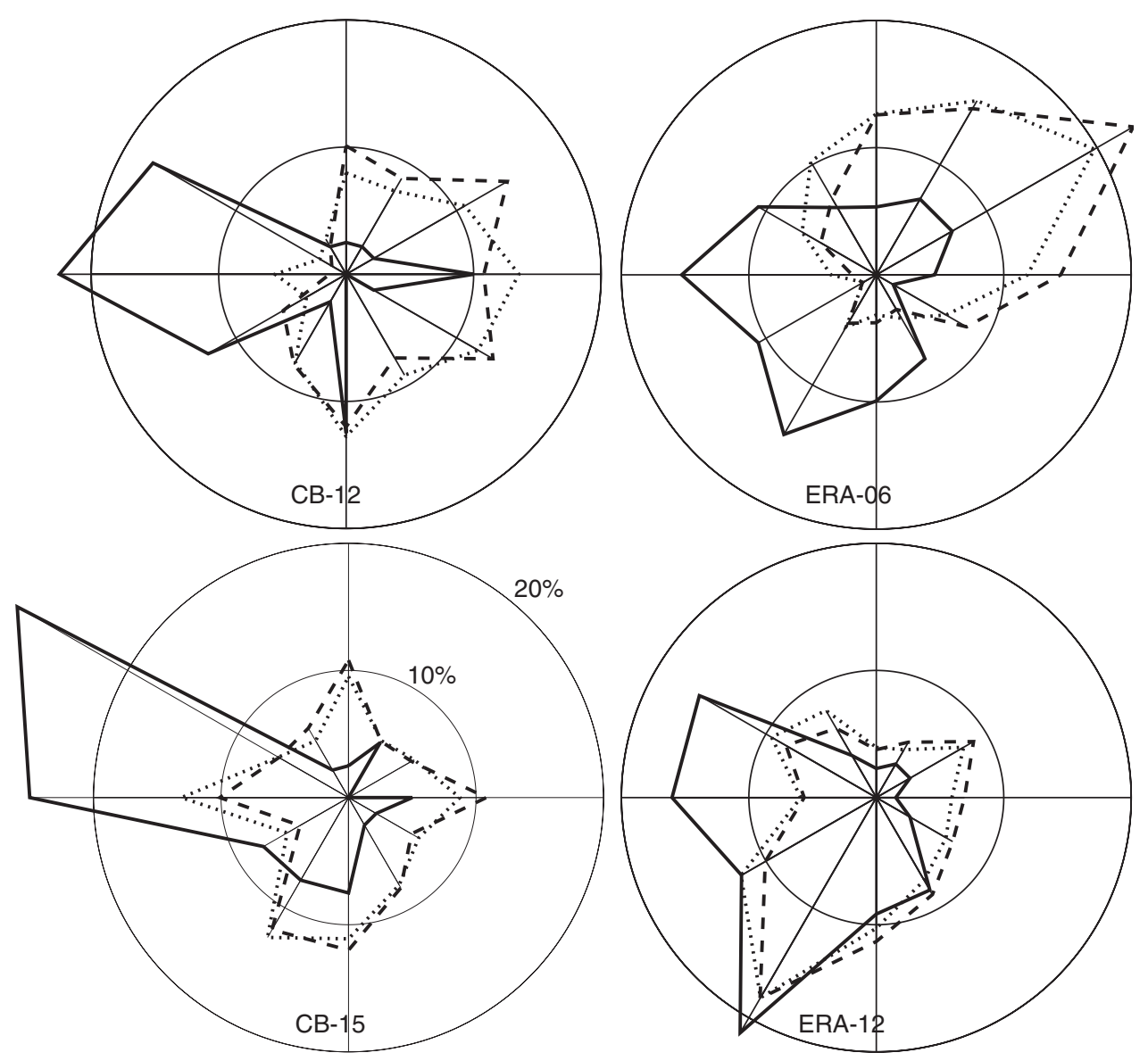

Fig. 13. Wind roses for Castelo Branco (CB) 1985-95: observed surface wind (1200 and 1500 hours UTC); ERA wind (from ERA40 data, see text) at $100 \mathrm{~m}$ above ground (0600 and 1200 hours UTC). Numbers given with $\mathrm{CB}$ and ERA indicate time. No wildland fires (full line); large wildland fires (BA $\geq 500 \mathrm{ha}$; dotted); very large wildland fires (BA $\geq 1000$ ha; broken). Wind directional frequencies are given that are summarized over sectors of $30^{\circ}$. The radial lines mark the sector's centre.

Table 2. Statistics of wildfires in five districts of central Portugal and Iberian thermal lows between 1980 and 2001 For definition of $z_{18}^{*}$ see text; BA, burnt area in ha; standard deviation, $\sigma$

\begin{tabular}{llccrrr}
\hline Data & & Sample days & Fire events $(\%)$ & $\overline{\mathrm{BA}}(\mathrm{ha})$ & $\sigma(\mathrm{ha})$ & $z_{18}^{*}(\mathrm{~m})$ \\
\hline $\mathrm{BA} \geq 0$ & Entire period & 2684 & 100.0 & 392 & 1105 & 7.5 \\
& No thermal low & 1356 & 47.2 & 393 & 1233 & 4.6 \\
& Thermal low & 1328 & 52.8 & 392 & 956 & 10.5 \\
\multirow{3}{*}{$\mathrm{BA} \geq 500$} & Entire period & 449 & 37.8 & 1949 & 2083 & 8.1 \\
& No thermal low & 210 & 18.5 & 2155 & 2470 & 5.6 \\
& Thermal low & 239 & 19.3 & 1767 & 1653 & 10.4 \\
\hline
\end{tabular}

daily difference between maximum and minimum temperature has its maximum of $4 \mathrm{~K}$ at lag time of zero days, being slightly weaker in the pre-event and very weak in the post-event phase.

Statistics of thermal lows and BA as consequence of wildland fires show a significant correlation between the BA and the monthly number of thermal low days. Additionally, a crosscovariance regression between heat lows and BA shows that the peak amount of BA occurs up to 3 days after the thermal low's occurrence. This suggests that in the fire's pre-phase, a northeasterly-to-easterly surface flow transports heated, dry air from the peninsula's centre towards Portugal, enhancing meteorological conditions for wildland fire. A Portuguese proverb describes the not always smooth relationship between Portugal and Spain: 'De Espanha nem bom vento nem bom casamento' ('From Spain, 


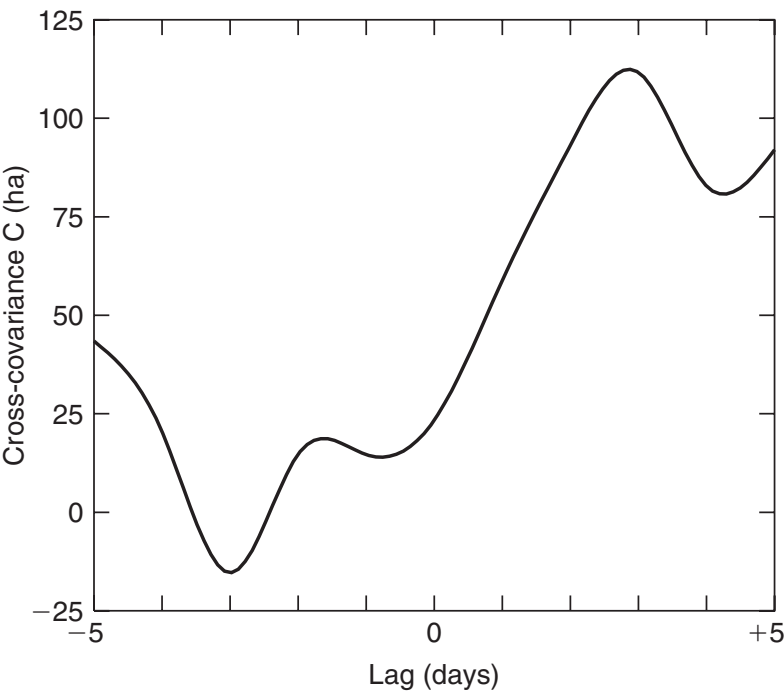

Fig. 14. Cross-covariances $\mathrm{C}\left(\mathrm{BA}, z_{18}^{*} \mid \tau\right)$ in ha as a function of lag.

neither a good wind nor a good marriage'). The present study seems to corroborate the first part of the proverb.

\section{Acknowledgements}

The present work was supported by the German Academic Exchange Service (DAAD), under project number D/05/50634, and the Gabinete de Relações Internacionais da Ciência e do Ensino Superior (GRICES) in Portugal. The second author thanks the Foundation for Science and Technology (Portugal) for a grant, SFRH/BD/10882/2002. Thanks go also to Miguel Cruz (DGRF, Portugal) for providing forest fire data. Finally, the project INTERFACE (POCI/AMB/60660/2004) is acknowledged.

\section{References}

Alcoforado MJ, de Almeida AF (1993) Incêndios no parque natural da Arrábida: dados estatísticos. (Fires in the Parque of Arrábida: statistical data). Finisterra, XXVIII 55-56, 229-241.

APIF (Agency for Forest Fire Prevention) (2005) Proposta Técnica de Plano Nacional de Defensa da Floresta contra Incêndios - Plano de Acção, Vol. II, pp. 446. (Lisbon)

Brotak EA, Reifsnyder WE (1977) An investigation of the synoptic situation associated with major wildland fires. Journal of Applied Meteorology 16 867-870. doi:10.1175/1520-0450(1977)016<0867:AIOTSS > 2.0.CO;2

Carvalho A, Flannigan MD, Logan K, Miranda AI, Borrego C (2008) Fire activity in Portugal and its relationship to weather and the Canadian Fire Weather Index System. International Journal of Wildland Fire 17, 328-338. doi:10.1071/WF07014

Conrad V (1943) The climate of the Mediterranean region. Bulletin of the American Meteorological Society 24, 127-145.

DGRF (Direcção Geral dos Recursos Florestais) (2006) Incêndios Florestais - Relatório 2005 (Forest fires - Report 2005). In 'Defensa da floresta contra incêndios'. (Eds DGRF) Available at http://www. afn.min-agricultura.pt/portal/dudf/informacoes/Resource/pdf/relatorio/ dgrf-if-relatorio2005.pdf [Verified 7 January 2009]
EC (European Commission) (1998) Common information system on forest fires, 1985-1997 study. European Commission, Directorate-General Agriculture, DG VI, FII-2. (Brussels, Belgium)

Flannigan MD, Wotton BM (2001) Climate, weather and area burned. In 'Forest Fires: Behaviour and Ecological Effects'. (Eds EA Johnson, K Miyanishi) pp. 349-373. (Academic Press: San Diego, CA)

Hoinka KP, Castro M (2003) The Iberian Peninsula thermal low. Quarterly Journal of the Royal Meteorological Society, 129, 1491-1511. (Corrigendum 2006). Quarterly Journal of the Royal Meteorological Society 132, 1377. doi:10.1002/QJ.200613261719

Hoinka KP, Gaertner M, Castro M (2007) Iberian thermal low in a changing climate. Quarterly Journal of the Royal Meteorological Society 133, 1113-1126. doi:10.1002/QJ.78

Jenkins MA, Clark T, Coen J (2001) Coupled atmospheric and fire models. In 'Forest fires: Behaviour and Ecological Effects'. (Eds EA Johnson, K Miyanishi) pp. 257-302. (Academic Press: San Diego, CA)

Lourenço L (1988) Tipos de tempo correspondentes aos grandes incêndios florestais ocorridos em 1986 no centro de Portugal. (Weather aspects of the large forest fires during the summer of 1986 in the centre of Portugal). Finisterra, XXIII 46, 251-270.

Pereira MG, Trigo RM, da Camara CC, Pereira JMC, Leite SM (2005) Synoptic patterns associated with large summer forest fires in Portugal. Agricultural and Forest Meteorology 129, 11-25. doi:10.1016/ J.AGRFORMET.2004.12.007

Ramos C, Ventura JE (1992) Um índice climático de perigo de incêndio aplicado aos fogos florestais em Portugal. (A daily climatic index of fire risk applied to Portugal). Finisterra, XXVII 53-54, 79-93.

Skinner WR, Stocks BJ, Martell DL, Bonsal B, Shabbar A (1999) The association between circulation anomalies in the mid-troposphere and area burned by wildland fire in Canada. Theoretical and Applied Climatology 63, 89-105. doi:10.1007/S007040050095

Skinner WR, Flannigan MD, Stocks BJ, Martell DL, Wotton BM, Todd JB, Mason JA, Logan KA, Bosch EM (2002) A 500-hPa synoptic wildland fire climatology for large Canadian forest fires, 1959-1996. Theoretical and Applied Climatology 71, 157-169. doi:10.1007/S007040200002

Trigo RM, Pereira JM, Pereira MG, Mota B, Calado TJ, Dacamara CC, Santo FE (2006) Atmospheric conditions associated with the exceptional fire season of 2003 in Portugal. International Journal of Climatology $\mathbf{2 6}$ 1741-1757. doi:10.1002/JOC.1333

Uppala SM, Kallberg PW, Simmons AJ, Andrae U, Da Costa Bechtold V, Fiorino M, Gibson JK, Haseler J, Hernandez A, Kelly GA, Li X, Onogi K, et al. (2005) The ERA re-analysis. Quarterly Journal of the Royal Meteorology Society 131, 2961-3012.

von Storch H, Zwiers FW (1999) 'Statistical Analysis in Climate Research ' (Cambridge University Press: Cambridge, UK)

Vásquez A, Moreno JM (1995): Patterns of fire occurrence across a climatic gradient and its relationship to meteorological variables in Spain. In 'Global Change and Mediterranean-Type Ecosystems'. (Eds JM Moreno, WC Oechel) pp. 408-434. (Springer Verlag: Berlin)

Viegas DX, Reis RM, Cruz MG, Viegas MT (2004) Calibração do sistema Canadiano de perigo de incêndio para aplicação em Portugal. (Calibration of the Canadian fire weather index over Portugal). Silva Lusitana 12, 77-93.

Viegas DX, Abrantes T, Palheiro P, Santo FE, Viegas MT, Silva J, Pessanha L (2006) Fire weather during the 2003, 2004 and 2005 fire seasons in Portugal. In 'Proceedings of the V International Conference on Forest Fire Research', 27-30 November 2006, Figueira da Foz, Portugal. (Ed DX Viegas) (CD-ROM) (ADAI/CEIF University of Coimbra: Portugal)

Manuscript received 6 March 2007, accepted 9 May 2008 